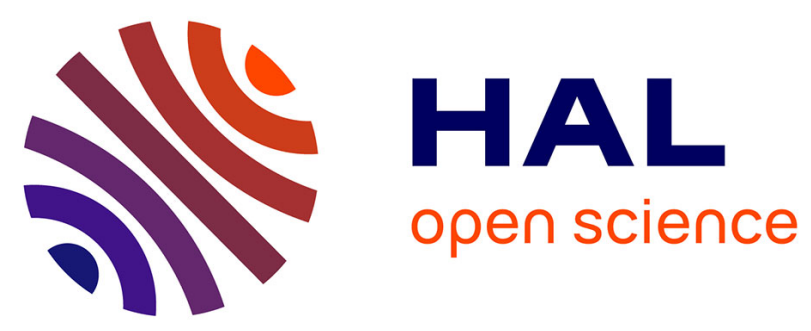

\title{
Brain damage: the endocranial cast of Mixtotherium cuspidatum (Mammalia, Artiodactyla) from the Victor Brun Museum (Montauban, France)
}

\author{
Maëva Judith Orliac, Hugo Bouaziz, Romain Weppe
}

\section{- To cite this version:}

Maëva Judith Orliac, Hugo Bouaziz, Romain Weppe. Brain damage: the endocranial cast of Mixtotherium cuspidatum (Mammalia, Artiodactyla) from the Victor Brun Museum (Montauban, France). MorphoMuseum, 2021, 7, 10.18563/journal.m3.158 . hal-03464281

\author{
HAL Id: hal-03464281 \\ https://hal.science/hal-03464281
}

Submitted on 20 Dec 2021

HAL is a multi-disciplinary open access archive for the deposit and dissemination of scientific research documents, whether they are published or not. The documents may come from teaching and research institutions in France or abroad, or from public or private research centers.
L'archive ouverte pluridisciplinaire HAL, est destinée au dépôt et à la diffusion de documents scientifiques de niveau recherche, publiés ou non, émanant des établissements d'enseignement et de recherche français ou étrangers, des laboratoires publics ou privés. 


\title{
Brain damage: the endocranial cast of Mixtotherium cuspidatum (Mammalia, Artiodactyla) from the Victor Brun Museum (Montauban, France)
}

\author{
Maëva Orliac ${ }^{1 *}$, Hugo Bouaziz ${ }^{1}$, Romain Weppe ${ }^{1}$ \\ ${ }^{1}$ Institut des Sciences de l'Évolution de Montpellier (UMR 5554, CNRS, UM, IRD, EPHE), c.c. 064, Université Montpellier, place Eugène Bataillon, \\ F-34095 Montpellier Cedex. \\ *Corresponding author: maeva.orliac@umontpellier.fr
}

\begin{abstract}
Our knowledge of the external brain morphology of the late Eocene artiodactyl ungulate Mixtotherium, relies on a plaster model realized on a specimen from the Victor Brun Museum in Montauban (France) and described by Dechaseaux (1973). Here, based on micro CT-scan data, we virtually reconstruct the 3D cast of the empty cavity of the partial cranium MA PHQ 716 from the Victor Brun Museum and compare it to the plaster model illustrated and described by Dechaseaux (1973). Indeed, the specimen from which the original plaster endocast originates was not identified by Dechaseaux by a specimen number. We confirm here that the studied specimen was indeed the one described and illustrated by Dechaseaux (1973). We also reconstruct a second, more detailed, model providing additional morphological and quantitative observations made available by micro CT scan investigation such as precisions on the neopallium folding and endocranial volumes.
\end{abstract}

Keywords: artiodactyl, Late Eocene, Quercy, brain endocast

Submitted:2021-09-21, published online:2021-11-25. https://doi.org/10.18563/journal.m3.158

\section{Inv nr. MAPHQ716 endocast of the brain cavity}

Table 1. Related model of Mixtotherium cuspidatum Collection: Muséum d'Histoire Naturelle Victor Brun, Montauban, France.

\section{INTRODUCTION}

Our knowledge of the paleoneurology of Paleogene artiodactyls widely relies on the works of C. Dechaseaux based on the exceptionally well-preserved specimens from the Quercy phosphorites (SW France). Dechaseaux (1973) partly described the endocast of Mixtotherium based on a plaster endocast realized on a "juvenile specimen" from the Quercy collections of the Victor Brun Museum in Montauban (Tarn-et-Garonne, France). She did not provide any information regarding the cranium from witch the endocasts derives, and did not identify the specimen by a number. Today, a partial cranium (MA PHQ 716; Fig. 1) pertaining to Mixtotherium, is exposed in the permanent exhibition of the Victor Brun Museum. It exhibits cut marks close to its sagittal plan and is a good candidate to correspond to the specimen prepared by Dechaseaux to describe the endocasts of this taxon. Here, based on micro CT-scan data, we virtually reconstruct the 3D cast of the empty cavity of MA PHQ 716 and compare it to the plaster model illustrated and described by Dechaseaux (1973). We also reconstruct a second, more detailed, model including additional observation made available by micro $\mathrm{CT}$ scan investigation and discuss the improvements brought by this method (see table 1).

Mixtotheriidae is a monogeneric family of endemic European artiodactyl, known from the middle Eocene (Mammalian Palaeogene level MP13-14; Sudre et al., 1990) to the upper
Eocene (MP17b-MP18) (Remy et al., 1987; Erfurt and Métais, 2007). Within Mixtotheriidae, the genus Mixtotherium is relatively well diversified and gathers seven species according to Erfurt and Métais (2007). Yet, recent edits were proposed regarding the specific content of the genus, with a probable synonymy between M. priscum and M. gresslyi (Hooker, 1986; Hooker and Weidmann, 2000) and a referral of M. lavergnensis to the genus Robiacina (Weppe et al. 2020). Mixtotherium is a very enigmatic animal. The type species M. cuspidatum, described by Filhol (1880), presents a puzzling mosaic of characters unique within European artiodactyls. Its cranial morphology is very reminiscent of that of large adapine primates (Leptadapis and/or Magnadapis Godinot and Couette, 2008), with a prominent sagittal crest, wide zygomatic arches, short and wide muzzle, and quite medially positioned orbits (illustration of Mixtotherium cranium in Stehlin, 1908:fig. 124-125). Its mandibular morphology is also particular, with a mandibular corpus very high in its posterior part (Stehlin, 1908:fig. 126), resembling that of extant hyracoids. Finally, its dental morphology is "more classical" and similar to that of other Eocene bunoselenodont artiodactyls, with a mesiolingual paraconule and protocone and a large distolingual metaconule, suggesting a mixed frugivorous/folivorous diet (Blondel, 2001). In terms of body mass, based on their dental measurements [ $\log$ mass $=\log \mathrm{LMRL} * 3.265$ - 0.536 (LMRL: lower molar row length; Janis, 1990] mixtotheriids weight from $2.8 \mathrm{~kg}$ (M. gresslyi) to $11 \mathrm{~kg}$ (M. cuspidatum). Various hypotheses have been proposed regarding the phylogenetic position of this family within Artiodactyla. Simpson (1945), based on cranial characters, placed Mixtotherium in a subfamily of Cebochoeridae. Gentry and Hooker (1988: fig. 9.8) in their manual 

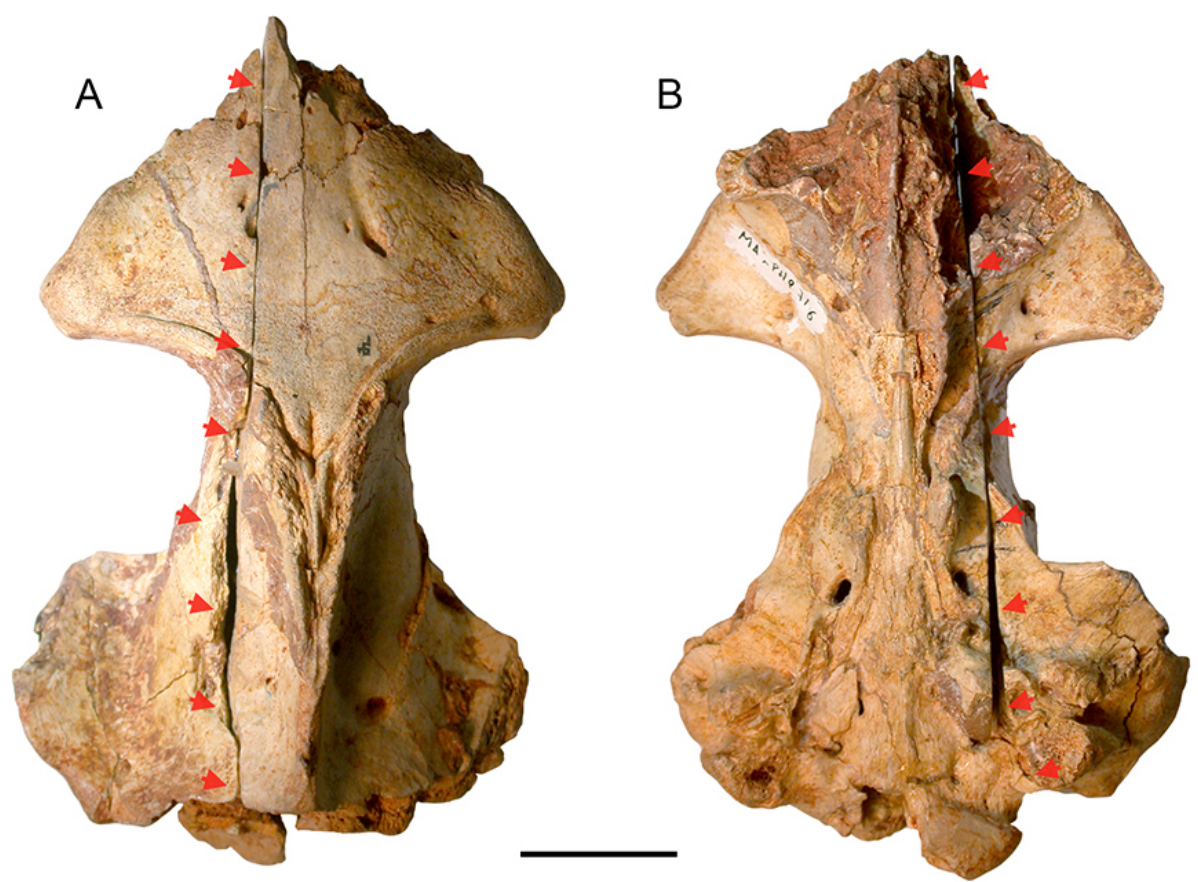

Figure 1. Partial cranium MA PHQ 716 attributed to Mixtotherium sp. and exposed in the permanent exhibition of the Victor Brun Museum in Montauban illustrated in A) dorsal and B) ventral views. The large cut suggesting preparation for endocasts extraction is visible on the left side of the specimen, highlighted by red arrows. Scale bar $=1 \mathrm{~cm}$.

cladogram, placed the Mixtotheriidae as the sister group of two North American families, Merycoidodontidae and Agriochoeridae; while with their PAUP* consensus cladogram (Gentry and Hooker 1988:fig. 9.7), Mixtotheriidae were positioned at the base of a wide clade including Anoplotherioidea, Xiphodontidae, Protoceratidae, Amphimerycidae, Ruminantia, and cameloids. Thereafter, Hooker and Weidmann (2000) allied Mixtotherium within Cainotherioidea, a clade including two other European endemic families, Robiacinidae and Cainotheriidae. This rapprochement was recently supported by Weppe et al. (2020; fig. 4), who retrieved Mixtotherium at the base of a clade gathering Anoplotheriidae and Cainotherioidea. Finally, Luccisano et al. (2020; fig. 7b) in a larger scale analysis, found Mixtotherium at the base of all European bunoselenodont families.

\section{METHODS}

The partial cranium MA PHQ 716 referred to as Mixtotherium sp. is curated in the Victor Brun Museum in Montauban. It was collected in Quercy area during the mining excavation that took place there at the end of the 19th and beginning of 20th century. Comparison with additional material of Mixtotherium from Basel museum (NMB QW 1749) indicates that it corresponds to Mixtotherium cuspidatum. The 3D data acquisition was performed at the $\mu \mathrm{CT}$ scanner facility of the Montpellier Ressources Imagerie platform (MRI) at the University of Montpellier, using an EasyTom $150 \mu \mathrm{CT}$ scanner. The voxel size is of $91 \mu \mathrm{m}$. Segmentation and measurements were performed using Avizo ${ }^{\circledR} 9.3$ (Thermo Fisher Scientific-FEI). Segmentation was performed manually slice by slice using the pencil segmentation tool by H.B. A first model corresponds to the extraction of the empty space left in the cranial cavity (Fig. 2 B, blue selection). It was originally not empty and results from a mechanical preparation removing the sediment that filled the cavity after the cranium burial. This first model mimes the rendering of a plaster model made out of the cranial cavity as it stands with the texture of the surface of the internal walls of the cranium, and the space cleared by the mechanical preparation. This "virtual plaster model" will allow for determining if this specimen corresponds indeed to the one published by Dechaseaux (1973). The plaster model illustrated by Dechaseaux (1937:fig. 3) is curated in the "plaster endocast collection" of the Museum National d'Histoire Naturelle, Paris. A second, more detailed, 3D reconstruction ("restored model") corresponds more accurately to the cast of the braincase and includes recrystallized areas and additional spaces still filled with sediments, as well as the right side of the specimen, removed for preparation constraints (Fig. 2 B, pink selection). The labelled 3D rendering of the complete Mixtotherium endocranium was performed with MorphoDig 1.6.4 software (Lebrun 2018). The "restored model" with labeled structures is available for download in .stl format. The literature relating to the study of external features of the brain abounds with diverse nomenclatures. We principally use here the revised nomenclature of Repérant (1971), mainly built on the work of Smith (1902) and Anthony and Grzybowski (1930) and based on various homology criteria (topographical, morphological, anatomical, histological, ontological, phylogenetic).

\section{INSTITUTIONAL ABBREVIATIONS}

MA, Museum Victor Brun, Montauban, France; MNHN, Museum National d'Histoire Naturelle, Paris, France; NMB, Natu- 
ral History Museum, Basel, Switzerland.

\section{DISCUSSION AND CONCLUSIONS}

\section{Correspondence with the plaster model described by Dechaseaux (1973)}

As illustrated on figure 3, the 3D model corresponding to the empty space in the braincase of MA PHQ 716, or "virtual plaster model", is similar to the plaster endocast illustrated by Dechaseaux (1973: fig. 3). The same structures can be identified with the same level of details, confirming our initial hypothesis that the specimen MA PHQ 716 was the one investigated by Dechaseaux (1973). The right olfactory bulb is only partly preserved, while the left one is missing. The general aspect of the surface of the casts, plaster and virtual, is irregular and seems to be corroded. This is due to recrystallization of calcite on the internal surface of the braincase that has not been removed by the preparation of Dechaseaux (Fig. 2 A-B; highlighted in pink on Fig. 2 B). Despite of the obscured detail of the model, the different structures and grooves detailed by Dechaseaux (1973) are clearly visible in dorsal and lateral views. Even if not figured in Dechaseaux (1973), the ventral aspect of the first 3D model corresponds to the description provided by the latter author, the surface is irregular and the structures are difficult to identify, which will be corrected here by the study of the second 3D "restored model".

\section{Restored model}

The "virtual plaster model" has a total volume of 16500 mm3. After addition of missing volume corresponding to calcite recrystallization and missing portions, the second model measures $19503 \mathrm{~mm} 3$ (which is still underestimated because of material loss due to the cutting of the cranium). Based on the complete model, the olfactory bulb chamber volume equals $2145 \mathrm{~mm} 3$, which represent 13\% of the total endocast volume. The restored model shows the different structures of the endocranium more clearly (Fig. $2 \mathrm{C}$ vs D). One of the main difference lies in the olfactory bulbs representation. The shape and the disposition of both olfactory chambers relative to each over appears clearly on the complete model. Both bulbs are joined on half of their length and then diverge with a $90^{\circ}$ angle. The cribriform plate is located on the anterior-most portion of the bulbs chamber, with a small ventral extension; there is a salient ridge outlining the external bordure of the cribriform area. The bulbs are separated from the cerebrum by a short circular fissure.

On the dorsal aspect of the cerebrum, the dorsal-sagittal sinus and the sulci are deeper than in the "virtual plaster model", as is the demarcation between the neopallium and the midbrain. The extension of the sulci can be observed with much accuracy on the complete 3D model, just like the line of the rhinal fissure. There are two main sulci on the neopallium, a long coronolateral and a suprasylvia, longitudinal and clearly separated from each other (Fig. 4 D). A faint, short oblique sulcus is also present on both sides of the model. The midbrain is widely exposed on the dorsal aspect of the endocast, but the colliculi are not visible. The cerebellum length measures less than half of that of the cerebrum (Table 2). The vermis is globular, wider than the cerebellar hemispheres. The latter are small and do not extend posteriorly to the level of the vermis. The surface of the vermis shows imprints of the cerebellar lobules, with more details in its anterior-most part and a wide depression that was possibly recognized as the fissura prima by Dechaseaux (1973). The posterior-most part of the vermis cannot be reconstructed because of breakage of the occipital aspect of the specimen.

In lateral view, like previously highlighted by Dechaseaux (1973), the very low aspect of the cerebrum relative to the cerebellum is striking: all the brain components are aligned and there is almost no basicranial flexure (Fig. 4 C). In this view, the cerebrum's height does not reach that of the cerebellum. The neopallium is delimited ventrally by a clear rhinal fissure that runs well above the level of the orbito-temporal canal. A short presylvia connects to the rhinal fissure in its anterior portion (Fig. 4 C). The pyriform lobe is high and salient, but the olfactory tubercle is nothing more than a very discrete swelling at the level of the optic chiasma. In lateral view, the width of the mesencephalon exposure is visible as the gap between the posterior edge of the neopallium and the anterior margin of the vermis. The later protrudes dorsally, and shows a deep inflexion of its dorsal surface, interpreted by Dechaseaux (1973) as a possible location of the fissura prima. The large superior petrosal sinus hides the cerebral hemispheres. The imprint of the medial surface of the petrosal bone shows the cast of the subarcuate fossa, housing the parafloccular lobe, and that of the internal acoustic meatus, pathway for the vestibulo-cochlear nerve (VII-VIII). The complete 3D model allows for describing the ventral surface of the endocast. On the ventral aspect of the restored model, the main exits of cranial nerves and blood vessel pathways are visible (Fig. 4 E). Their pattern is similar to other Eocene artiodactyls, with rather anterior optic chiasma, a sphenorbital fissure and an individualized oval foramen. There is no imprint of a hypophyseal fossa. Posteriorly, the area of the medulla oblongata is flat and very wide.

The contribution of the 3D "restored" model based on microtomography data is significant and provides additional details on the morphology of the olfactory bulbs, the sulci pattern of the neopallium, and the morphology of the ventral surface. The 3D model also allows for measuring the total volume of the endocast and the volume of the olfactory bulbs. Based on a plaster model deriving from the cast of the mechanically prepared braincase cavity, Dechaseaux (1973) could observe two grooves on the neopallium, the suprasylvia and the coronolateral. The investigation of the CT slices indicates the presence of a small oblique sulcus and of a presylvia that were not visible on the plaster model studied by Dechaseaux (1973). Dechaseaux (1973) notes the specificity of the endocranium of Mixtotherium and its archaic aspect. The encephalon is indeed elongated and of small volume with a remarkable low height of the telencephalon, and the elements are aligned with each other. Along with these apparently plesiomorphic features, Mixtotherium shows a unique sulci pattern of the neopallium with a long coronolateral parallel to the suprasylvia, and a small oblique sulcus. Junction of the 

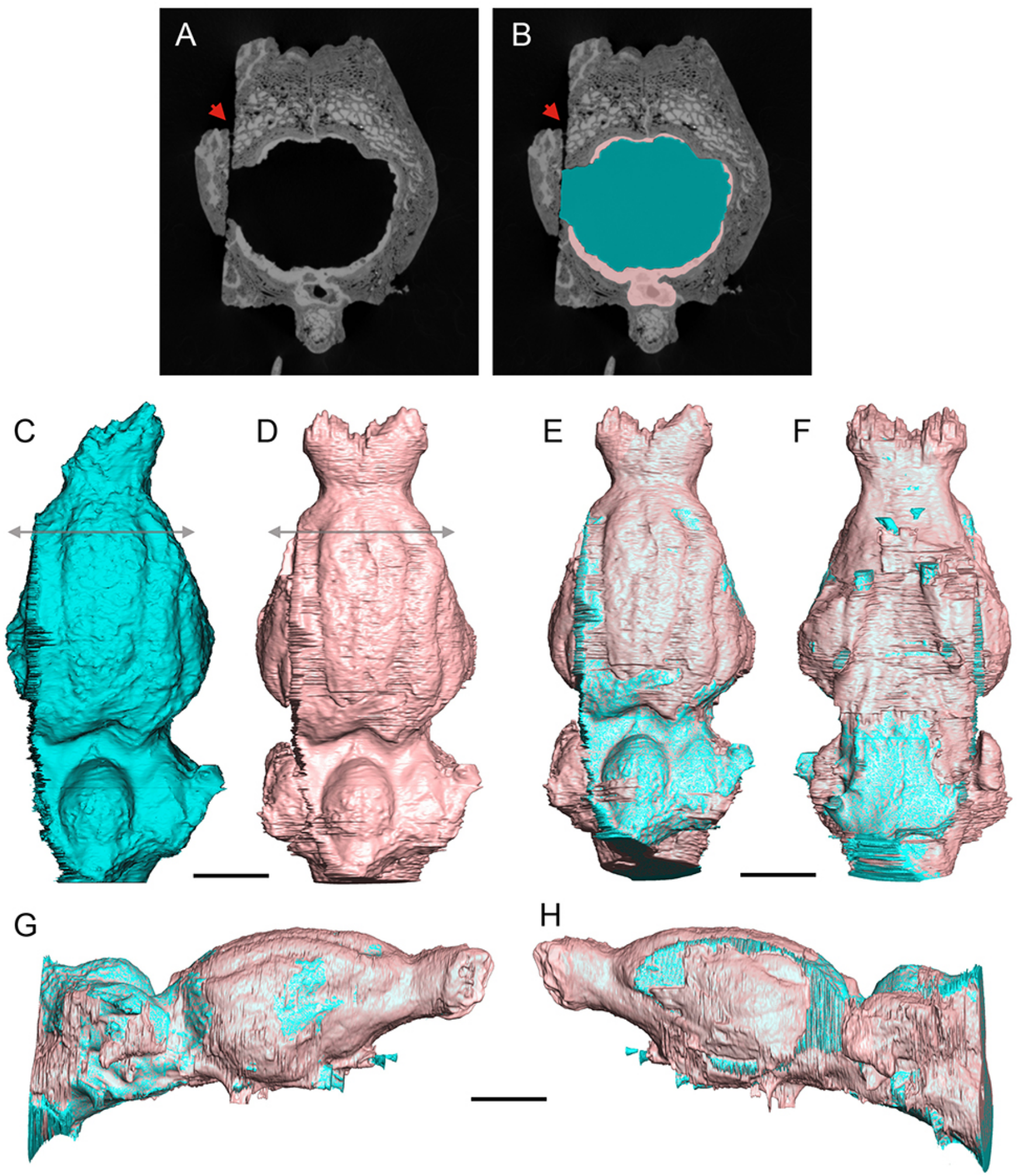

Figure 2. Illustration of selection and $3 \mathrm{D}$ rendering of the two endocasts models deriving from MA PHQ 716 . A) and B) illustrate the segmentation protocol on CT scan slices, in B) the blue selection corresponds to the empty space which selection led to the "virtual plaster model" (blue model), the pink selection corresponds to the selection of the empty space + calcite recrystallization on the internal surface of the brain case and led to the "restored model" (pink model); C) and D) illustrate the "virtual plaster model" and the "restored model" respectively, in dorsal view; E)-H) illustrate the contribution of the "restored model" relative to the initial "virtual plaster model" in E) dorsal, F) ventral, G) right lateral, and H) left lateral views. Grey double arrows indicate the location of the CT slice illustrated in A) and B); the preparation cut is highlighted by red arrows. Scale bar $=1 \mathrm{~cm}$. 


$\begin{array}{cllll}\text { Structure } & \text { Volume }(\mathbf{c m} 3) & \text { Length }(\mathbf{c m}) & \text { Breadth }(\mathbf{c m}) & \text { Height }(\mathbf{c m}) \\ \text { Whole endocast } & 19.50 & 6.35 & & \\ \text { Olfactory bulbs } & 2.15 & 11.17 & 1.70 & 1.10 \\ \text { Cerebrum } & & 3.36 & 3.02 & 2.27 \\ \text { Mesencephalon } & & 0.37 & 1.76 & 1.47 \\ \text { Cerebellum } & & 1.50 & 2.32 & 2.47\end{array}$

Table 2. Measurements of the restored model. All measurements correspond to maximal values.
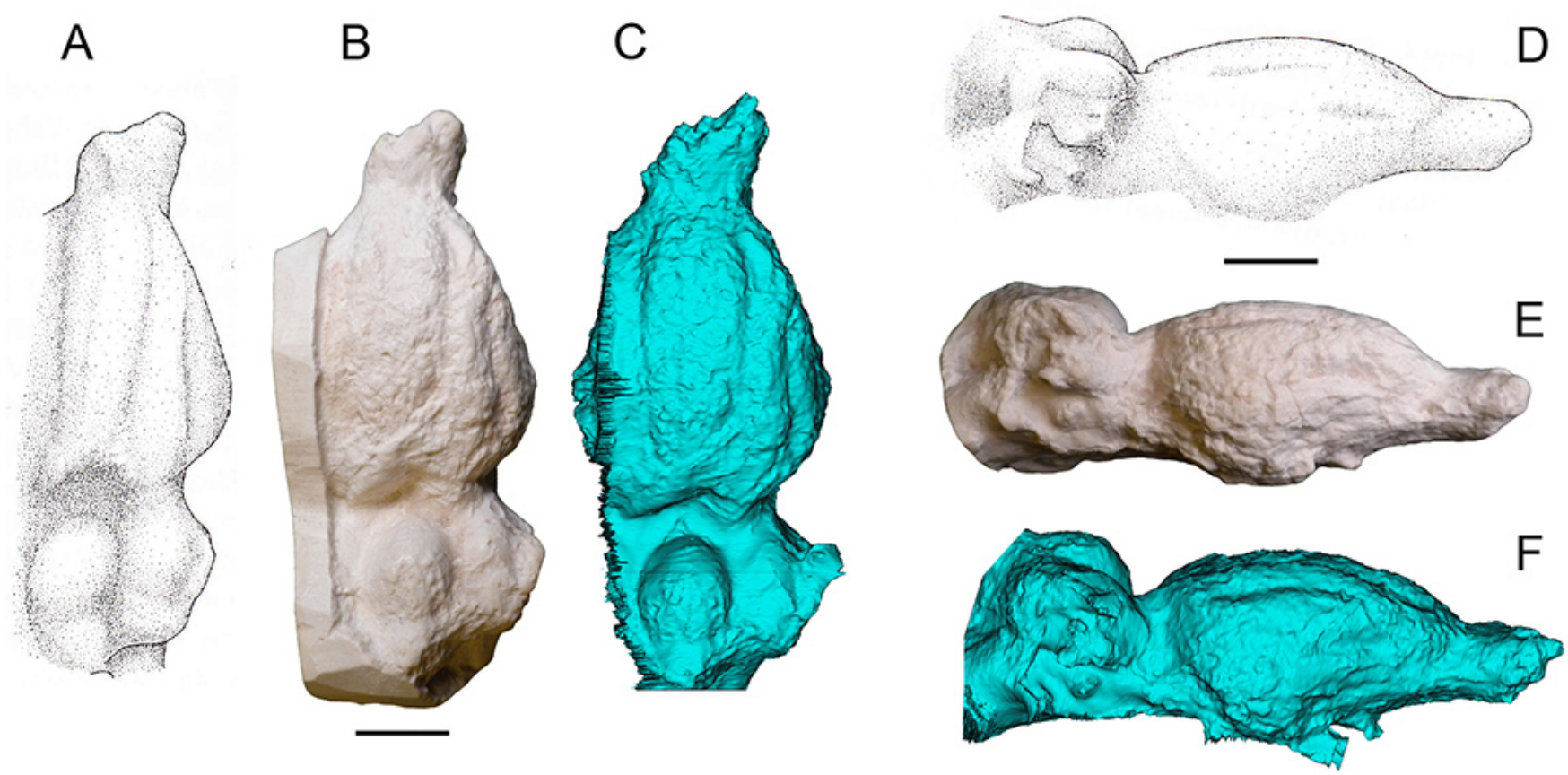

Figure 3. Comparison of the endocast illustrated by Dechaseaux (1937:fig.3) (A, D) with the plaster endocast from the MNHN collections (B, E) and the "virtual plaster model" deriving from MA PHQ $716(\mathrm{C}, \mathrm{F})$, illustrated in A)-C) dorsal and D)-F) right lateral views. Scale bar $=1 \mathrm{~cm}$.

coronal to the lateral which parallel the suprasylvia and delimits a long, protruding gyrus 3 recalls the pattern of Diplobune (Dechaseaux, 1969: fig. 7), just as the presence of oblique sulcus, and the globular vermis, protruding dorsally, with a posteriorly located fissure prima (Fig. 5). This pattern is derived compared to the almond shape gyrus observed in Diacodexis, homacodontids and some European endemic taxa such as $\mathrm{Ce}$ bochoerus, Tapirulus, or Mouillacitherium (Orliac and Gilissen, 2012; Dechaseaux, 1969). The morphological similarity between the brain of Mixtotherium and Diplobune is congruent with the close phylogenetic affinities between Mixtotherium and anoplotherids as supported by their dental morphology by Weppe et al. (2020). Compared to other Eocene species such as Diacodexis (Orliac and Gilissen, 2012) or Dichobune (Orliac and Thewissen, 2021), Mixtotherium shows strikingly different olfactory bulbs chambers, with more square outlines and divergent orientation. The location of the brain in the cranium is also quite unusual, and rather posterior compared to the location of the orbits: the cerebrum entirely lies posterior to the postorbital process, like what has recently been described in raoellids (Orliac and Thewissen, 2021). This particularity might have to be put in relation with the wide zygomatic arches and the big sagittal crest, testifying to the presence of big masticatory muscles. The whole cranial architecture of Mixtotherium indicates the presence of a strong masticatory apparatus. There might be a link between the constraints on the braincase walls implied by the masticatory muscles and the lack of basicranial flexure and "low" aspect of the brain in Mixtotherium. Finally, this study allows for attributing the plaster endocast described by Dechaseaux (1973) today curated in the Museum National d'Histoire Naturelle in Paris, to the partial cranium MA PHQ 716 from the Victor Brun Museum collections in Montauban.

\section{ACKNOWLEDGEMENTS}

We are grateful to Aude Medina (Victor Brun Natural History Museum, Montauban) for welcoming us in the collections and to $\mathrm{S}$. Ladevèze for providing us with the 3D model of Diplobune secundaria. We thank the MRI platform, member of the national infrastructure France-BioImaging supported by the French National Research Agency [ANR-10-INBS-04, «Investments for the future $\gg$ ], the LabEx CEMEB [ANR-10-LABX-0004] and NUMEV [ANR-10-LABX-0020]). This work was financially supported by the ANR program DEADENDER (ANR-18-CE020003-01) headed by M. J. Orliac. 


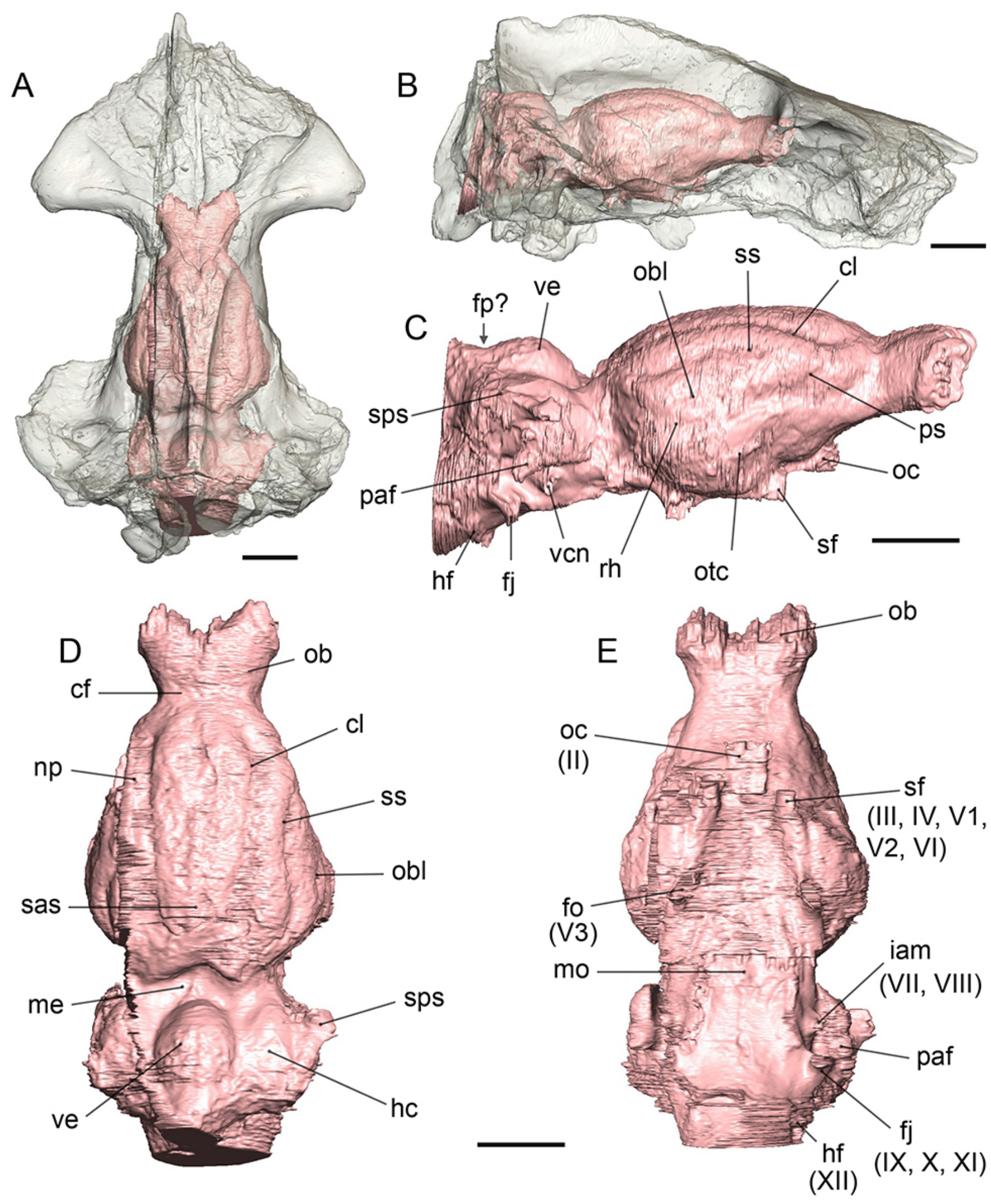

Figure 4. In situ location through a translucent rendering of the cranium (A and B) and morphological features of the endocast of Mixtotherium cuspidatum (restored model, MA PHQ 716). A) and D), dorsal, B) and C) right lateral, E, ventral views. Abbreviations: cf, circular fissure; cl, coronolateral sulcus; fj, foramen jugulare; fp, fissure prima; hc, cerebral hemispheres; hf, hypogloss foramen; iam, internal auditory meatus cast; me, mesencephalon; mo, medulla oblongata; np, neopallium; ob, olfactory bulbs; obl, oblique sulcus; oc, optic chiasma; otc, orbito-temporal canal; paf, parafloccular lobe; ps, presylvia; rh, rhinal fissure; sf, sphenoidal fissure; sas, sagittal sinus; sps, superior petrosal sinus; ss, suprasylvia; ve, vermis. II to XII refer to cranial nerves. Scale bars $=1 \mathrm{~cm}$ M3 Journal 7:e158 


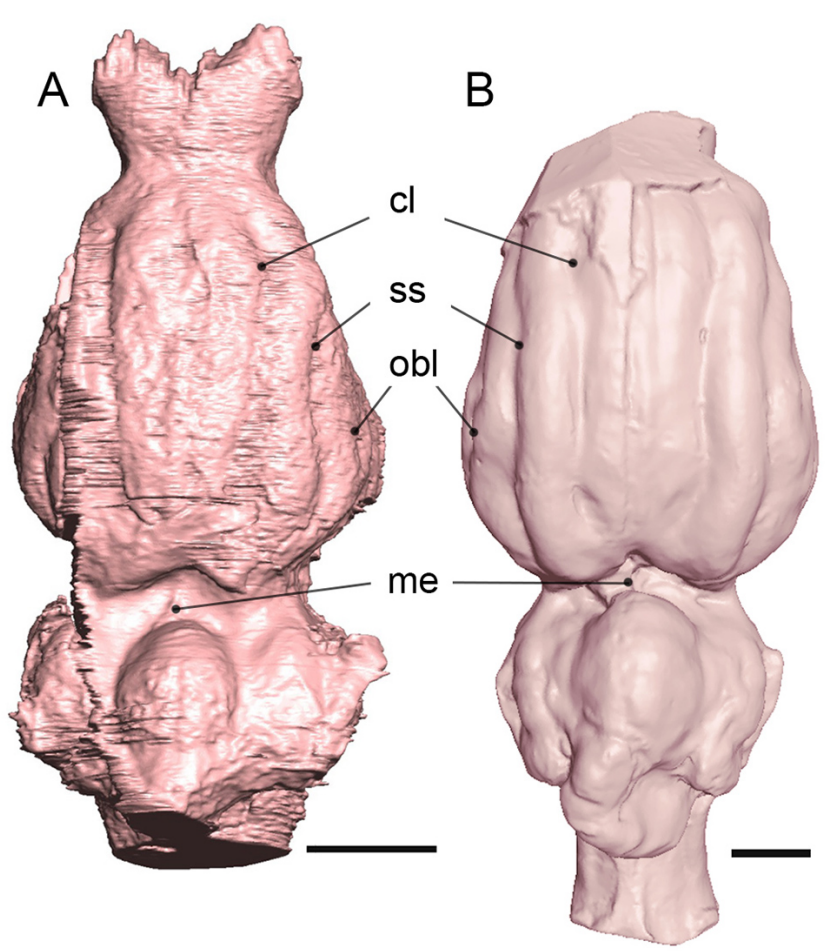

Figure 5. Comparison of the dorsal views of A) the endocast of Mixtotherium cuspidatum (restored model, MA PHQ 716) and B) the endocasts of Diplobune secundaria (MNHN 2003-1). Abbreviations: cl, coronolateral sulcus; me, mesencephalon; obl, oblique sulcus; ss, suprasylvia. Scale bars $=1 \mathrm{~cm}$.

\section{BIBLIOGRAPHY}

Anthony R., Grzybowski J. 1930. Le Neopallium des Équidés: Étude du Développement de ses Plissements. Journal of Anatomy 64(2), 147-169.

Blondel C. 2001. The Eocene-Oligocene ungulates from Western Europe and their environment. Palaeogeography, Palaeoclimatology, Palaeoecology 168(12), 125-139. https://doi.org/10. 1016/S0031-0182(00)00252-2

Dechaseaux C. 1969. Moulages endocrâniens d\&\#39;artiodactyles primitifs. Essai sur 1\&\#39; histoire du néopallium. Annales de Paléontologie 60, 195-248.

Dechaseaux C. 1973. Essais de paléoneurologie. Annales de Paléontologie 59(1), 115-132.

Erfurt J., Métais G. 2007. Endemic European Paleogene artiodactyls: Cebochoeridae, Choeropotamidae, Mixtotheriidae, Cainotheriidae, Anoplotheriidae, Xiphodontidae, and Amphimeryci-

dae. In: Prothero D. R., Foss S.E. (Eds.), The Evolution of Artiodactyls. Johns Hopkins University Press, Baltimore, pp. 59-84.

Filhol H. 1880. Sur la découverte de mammifères nouveaux dans les dépôts de phosphate de chaux du Quercy. Comptes rendus de l'Académie des Sciences, Paris 90, 1579-1580. https: //doi.org/10.5962/bhl.part.14445

Gentry A. W., Hooker J. J. 1988. The phylogeny of the Artiodactyla. In: Benton M. J. (Ed.) The phylogeny and classifica- tion of the tetrapods: Volume 2, mammals. Clarendon Press, Oxford, pp. 235-272.

Godinot,M., Couette S. 2008. Morphological diversity in the skulls of large adapines (Primates, Adapiformes) and its systematic implications. In: Sargis E. J., Dagosto M. (Eds.), Mammalian Evolutionary Morphology. Springer, Dordrecht, pp. 285-313. https://doi.org/10.1007/978-1-4020-6997-0_12

Hooker J. J. 1986. Mammals from the Bartonian (middle/late Eocene) of the Hampshire Basin, southern England. Bulletin of the British Museum of natural History (Geol.) 39(4), 191-478.

Hooker J. J., Weidmann M. 2000. The Eocene mammal faunas of Mormont, Switzerland: systematic revision and resolutions of dating problems. Schweizerische Paläontologische Abhandlungen 120, 1-143.

Janis C. 1990. Correlation of cranial and dental variables with body size in ungulates and macropodoids. In: Damuth J., MacFadden B. J. (Eds.), Body size in mammalian paleobiology: estimation and biological implications. Cambridge, UK: Cambridge University Press, pp. 255-300. doi:10. 1046/j.14209101.1992.5030530.x

Lebrun R. 20018. MorphoDig, an open-source 3D freeware dedicated to biology. IPC5, Paris, France - 07/2018.

Luccisano V., Sudre J., Lihoreau F. 2020. Revision of the Eocene artiodactyls (Mammalia, Placentalia) from Aumelas and SaintMartin-de-Londres (Montpellier limestones, Hérault, France) questions the early European artiodactyl radiation. Journal of Systematic Palaeontology 18(19), 1631-1656. https://doi.org/ 10.1080/14772019.2020.1799253

Orliac M. J., Gilissen E. 2012. Virtual endocranial cast of earliest Eocene Diacodexis (Artiodactyla, Mammalia) and morphological diversity of early artiodactyl brains. Proceeding of the Royal Society B 279(1743), 3670-3677. https://doi.org/10. 1098/rspb.2012.1156

Orliac M. J., Thewissen J. G. M. 2021. The endocranial cast of Indohyus (Artiodactyla, Raoellidae): the origin of the cetacean brain. Journal of Mammalian Evolution pp 1-13. https://doi.or g/10.1007/s10914-021-09552-X

Remy J. A, Crochet J. Y., Sigé B., Sudre J., De Bonis L., VianeyLiaud M., Godinot M., Hartenberger J. L., Lange-Badré B., Comte B. 1987. Biochronologie des phosphorites du Quercy: mise à jour des listes fauniques et nouveaux gisements de mammifères fossiles. Münchner Geowissenschaftliche Abhandlungen 10(A), 169-188.

Repérant J. 1971. Morphologie comparée de 1\&\#39;encéphale et du moulage endocrânien chez les Tylopodes actuels (Mammifères, Artiodactyles). Bulletin du Muséum National d'Histoire Naturelle 4(4), 185-321.

Simpson G. G. 1945. The principles of classification and a classification of mammals. Bulletin of the American Museum of natural History 85, 1-350.

Smith G. E. 1902. On the homologies of the cerebral sulci. Journal of Anatomy and Physiology 36, 309-319. 
Stehlin H.G. 1908. Die Säugetiere des Schweizerischen Eocaens, Cristischer Catalog der Materialen, Tome 5. Abhandlungen der schweizerischen paläontologischen Gesellschaft 34, 691-837.

Sudre J., Sigé B., Remy J.-A., Marandat B., Hartenberger J.L., Godinot M., Crochet J.-Y., 1990. Une faune du niveau d\&\#39; Egerkinger (MP 14; Bartonien inférieur) dans les phosphorites du Quercy (Sud de la France). Palaeovertebrata 20(1), $1-32$.

Weppe R., Blondel C., Vianey-Liaud M., Escarguel G., Pélissié T., Antoine P.O., Orliac M. J. 2020. Cainotheriidae (Mammalia, Artiodactyla) from Dams (Quercy, SW France): phylogenetic relationships and evolution around the Eocene-Oligocene transition (MP19- MP21). Journal of Systematic Palaeontology 18(7), 541-572. https://doi.org/10.1080/14772019.2019.1645 754 